\title{
Dispositifs at play: Artists' moving image in the gallery
}

Ella Barclay and Alex Munt

\section{Introduction}

In one of the interviews conducted for this research, we spoke with Bree Pickering, the director at the Murray Art Museum (MAMA) who offered: "I can fairly confidently say that Australian video artists are leading the way in terms of video art, especially as it relates to integrating installation into the conceptual and material process" (B. Pickering, personal communication 10 June 2018). Here, Pickering mirrors the primary aim of this chapter, to ascertain the relationship between the conceptualisation of contemporary artists' moving image work and the ways in which this informs its installation in the gallery, and the experience of art audiences. Moreover, her view confirms our intuition that Australian artists working in moving image production are holding their own on the global stage. Prior to her role at MAMA, Bree Pickering was based in the United States, as museum director at Vox Populi in Philadelphia and before that, curator of the Australian Embassy in Washington D.C. In other words, hers is an informed and respected opinion.

With a focus on the Australian context, we have chosen to profile recent work from four emerging to mid-career Australian artists working with the moving image in contemporary art spaces: Brian Fuata, Pia van Gelder, Biljana Jancic and Angelica Mesiti. Given the parameters of a concise chapter, this is a finite selection of artists. Our criteria were based on two main elements. Firstly, that the artists selected have engaged at a sophisticated level in relation to the installation of their work in a gallery environment, and in relation to the way in which the work meets an audience. Secondly, and more phenomenologically in nature, we wanted to write about work we had experienced ourselves. The four exhibitions discussed here were held in Sydney spaces from 2012 to 2018. The research includes interviews conducted with the artists and curators involved. We were keen to have their voices interspersed within the critical and scholarly framework provided. This chapter aims to contribute to work on recent artists' moving image and be of interest to scholars, moving image artists and those engaged in the hybridisation of research and production activities in 'creative practice research' as a (relatively) new model of humanities research within the academy (see Batty and Kerrigan, 2018).

\section{Sub-heading 1}


Since the 1990s there has been a clear upward trend in the degree of moving image artworks produced and shown in contemporary galleries and art spaces. For curator Michael Newman, 'it has become practically impossible to walk around the gallery district of a major city, or visit a biennial, triennial or art fair, without seeing a large number of artworks consisting of images that move' (Comer, 2009, p. 88). In fact, for artist and theorist Hito Steyerl, contemporary biennials program a duration of moving image artworks in excess of what it is possible to theoretically consume within a given time period (Steyerl \& Berardi, 2012). With the migration of the moving image from the cinema theatre to the art gallery there has been a radical shift in the way in which an audience arrives at the work. For screen and architectural theorist Giuliana Bruno, 'motion pictures have now actually moved. To a certain extent, they have changed address' (Bruno, 2007). For theorist Erika Balsom (2013), the "Black Box/White Cube" dichotomy is significant, in that

the object found within the art gallery is framed by the space around it in such a manner as to radically change the meanings attached to it. Accordingly, the exhibition space must not be seen as a mere container, but a meta medium to be investigated. It is the means by which art is made visible and knowable to those who consume it.

The hybridisation of moving image artworks is of interest here, and so we set out specifically to examine the ways in which works met their audience. Questions of the diversity, spatiality and site-specificity of artists' moving image will be explored in relation to our case studies below. We aim to show the ways in which the contingency of contemporary art spaces white, or increasingly grey (industrial) cubes - informs the conception, production and installation of the work.

In order to understand the ways in which artists approach the installation of moving image work for the gallery, the concept of the dispositif proves useful. Balsom employs this term when she says, 'the gallery does not simply serve as a neutral, protective container for the moving image, but produces a new cinematic dispositif through its particular discursive and institutional framing and the various practices associated with it' (Balsom, 2013). To add to this, screen theorist Adrian Martin (writing about 'black box' and 'white cube' scenarios) refers to the dispositif as an 'arrangement or set-up of interrelated pieces or elements' (Martin, 2014). He speaks to the dual status of the dispositif in that it operates as both 'a mixture of aesthetic properties and social-historical conditions' (Martin, 2014:189). That is, the dispositif may refer to the historical passage of the moving image across eras or in relation to the distinct properties of a particular artwork or exhibition. The theoretical 
armature of the dispositif is grounded in poststructuralism and is often linked to Raymond Bellour's La Querelle des dispositifs (The Quarrel of the Dispositifs) (Bellour, 2012), in which he contrasts the traditional black box 'cinematic' dispositif with the excessive heterogeneity - near singularity - of white cube dispositifs at play in the gallery. Film theorist Daniel Fairfax highlights this, in his translation of Bellour, for a recent issue of Senses of Cinema devoted to 'Cinema and the Museum':

the author argues in favour of a clear distinction between the cinematic dispositif (a term French film theory uses to refer not only to the apparatus of filmic recording and projection, but to the system of viewing practices as a whole), and the multiple, ceaselessly re-invented dispositifs of moving images as displayed in galleries... for what he dubs "the quarrel of the dispositifs. (Bellour, 2018: para. 1)

For Martin, another way to describe the 'ceaseless reinvention' of dispostifs for artists' moving image work is to say that, in fact, 'installation could be another workable translation of dispositif'. Martin notes the work of Anne-Marie Duguet (1988) in her 'pioneering' application of the dispositif in art criticism (Duguet, 1988:188). This synchronises with our analysis of the Australian artists discussed here, who offer diverse approaches to the installation of their work with regard to the space of the gallery and an intended audience experience. Starting from an understanding of the dispositif as 'the arrangement of diverse elements in such a way to trigger, guide and organise a set of actions' (Martin 2014: 179), these case studies aim to uncover the dispositifs at play for the works discussed.

\section{[1] Document}




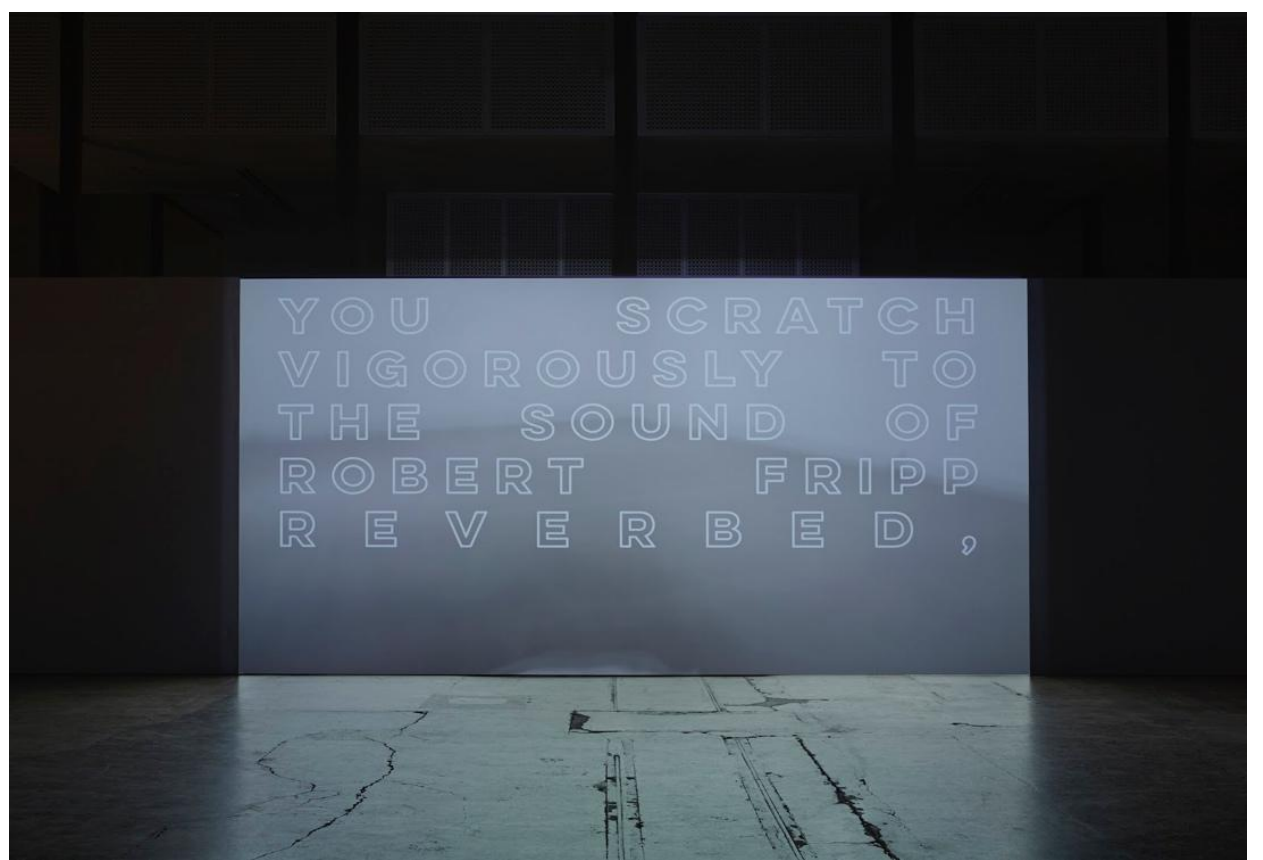

Figure 1: Apparitional Charlatan - A Revisionist Account of an Arbitrary Historical Category of Dance Film is a Performance of our Time Together on Stage Before Class... (2015). Brian Fuata. Photo: Zan Wimberly. Courtesy of the artist.

Art curator Chrissie Iles notes that most artists arrived to the moving image medium (from the late 1950s) from practices held in sculpture, photography, drawing, sound or performance (Iles and Whitney Museum of American Art, 2001: 34). In this context, the wider historical art movements of pop-art, minimalism, conceptual and performance-based art were (re)calibrated with respect to the 'new' medium, arriving in the gallery. In performance art, a convergence took place between the radical art practices of this domain and the accessibility of consumer grade film and video recording technologies to document the experimental, often controversial works for posterity. Seminal artists working with moving image-based documentation of their work in the gallery included Mike Parr, Marina Abramovic, Yayoi Kusama and Chris Burden.

Shoot (Burden, 1971) is an early example where film footage was recorded depicting the artist being (actually) shot in the gallery and contributed a significant dimension to the 'work' - post event. This confluence led to questions of the status and authenticity of an artwork which could be taken as either the performance itself, or its documentation as moving image. Art historian Peggy Phelan is one who is sceptical of the divide between ephemeral performance art in the gallery and its representation which serves to commodify an inherently disruptive, political and transient art practice. She says, 'performance honours the idea that a 
limited number of people in a specific time/place can have an experience of value which leaves no visible trace afterward' (Phelan, 1993, p.18). However, this view is largely outmoded today with a reassessment of the documentation of performance art as an important legacy, archive and resource for younger artists. The founding curator and director of Performa New York, Roselee Goldberg, asserts, 'the history of documentation is the history of performance' (Giannachi and Westerman, 2017: 26).

Brian Fuata is a contemporary artist who has engaged with the history, and tension, between performance art in the gallery and its documentation. Fuata is of Samoan descent and works across moving image and performance-based art. He has garnered an international reputation for an interpolation of media. His Apparitional Charlatan - A Revisionist Account of an Arbitrary Historical Category of Dance Film is a Performance of our Time Together on Stage Before Class... (Fuata, 2015) is a moving image artwork rendered in the form of an Apple Operating System (OS) screensaver. The work was conceived for, and installed, as a large-scale work within the 'grey cube' at Carriageworks in Redfern, Sydney, as a part of the group exhibition, Twenty-Four Frames in 2015. Fuata engaged a videographer to document his a priori performance (bodily performance in front of the camera) within a 'white cube' contemporary art gallery nested within the industrial architecture of Carriageworks - the Anna Schwartz Gallery.

He then removed his bodily presence from the documentation, leaving the gallery space as the visual residue. The result is an endless loop of roaming camera shots through the empty white gallery space. Fuata then worked with installation and sound designer Dave Meckin to superimpose 214 randomly ordered slides which featured text drawn from the artists' notes from consuming 78 performance videos, curated by American poet Kenneth Goldsmith for his online repository of experimental and artists' moving image Ubuweb (Goldsmith, 2011). The notes refer to documentation videos of performance art across the $20^{\text {th }}$ century, including of work from Xavier Le Roy, Gordon Matta-Clark, Yvonne Rainer and Carolee Schneeman. Fuata's notes and phrases extracted from the archive materialise as large scale, white text superimposed over images of the empty white cube gallery space. Any trace of Fuata's body is erased in the montage.

Apparitional Charlatan forms an exploration of the relationship between the forms and aesthetics of digital media and the history of performance art, and its documentation in the 
gallery. The work engages with notions of presence and absence, and speaks to the transience of the medium. Fuata says: 'I was primarily thinking about performance documentation as itself a live performance. The work presents a simple idea of liveness to be an infinitesimal configuration of set content' (B. Fuata, personal communication 25 April 2018). While arguably viewing the documentation of performance presents a less transformative experience than a live encounter with the work, the sheer excess of archival artists' moving image accessible in online archives today allows contemporary artists to build extensive personal knowledge bases that, in turn, can be referenced and resurrected in their own moving image-based gallery practices. The components of Fuata's dispositif for Apparitional Charlatan might be summarised as: the erasure/disappearance of the body of the artist; the projection of generic 'white cube' gallery spatiality within a 'grey cube' art space; and the 'remediation' (Bolter and Grusin, 1999) of video documentation in the form of a desktop OS screensaver which is generated by an algorithm to randomly generate the artwork, providing a new iteration for each viewer. This playful execution of a performance work concurs with the articulation of a dispositif as 'a game with rules, where the execution of the game's moves - the following of the rules - generates outcomes' (Martin, 2014: 179, his emphasis)

\section{[2] Signal}

The year 1963 is significant for artists' moving image as the year in which the consumer television set was hijacked as both sculptural form and medium. For Exposition of Music Electronic Television at Galerie Parnass, Nam June Paik installed twelve domestic TV sets, modified to disrupt signals and images from live broadcasting, while Wolf Vostell's Television Dé-collage at Smolin Gallery encouraged the audience to interact with six TV sets as a 'collage' of moving images the same year (Bennett, 2016). A.L. Rees, experimental film and video theorist, citing the work of video 'glitch' pioneers Woody and Steina Vasulka, notes that 'Video art was also medium-specific in its early days, exploiting direct playback as well as interference with the electronic signal' (Manasseh, 2009: 59). The installation of the monitor within the gallery (a space historically reserved for painting and sculpture) and the notion of wilful error, or deliberate misuse, linked to audience participation, resurfaces in recent moving image artworks by Pia van Gelder. In her Eyes Without a Face (2012) and AV Bells (2011), van Gelder invites the art gallery audience to interact with and 'regenerate' the artwork using patterns of signal interference delivered by bespoke machines. Consistent with Brian Fuata's Apparitional Charlatan, van Gelder exploits the factors of contingency which 
defines artists' moving image in the gallery. This serves as another example of the way in which audiences today meet, and interact, with contemporary moving image works.

I always imagine myself as being the person who sets up the opportunity for the machine to be listened to. I think they're the doers and I'm the facilitator. But if this facilitating is the only thing that the audience notices, they are responding through a preconceived hierarchy. The interactions are never meant to be solos because I am trying to reveal a collaboration between machines and [the user]. (Barclay, 2011)

For Eyes Without a Face, the viewer is invited to interact with an analogue modular synthesiser triggered by hand gestures. A camera is positioned above a table, with a small spot light on the table, so that when a viewer places their hands on the table, they see their hands appear on the monitor and are able to modify and play with different sound and video waves via hand articulations. This work speaks to the 1970s video art of Steina and Woody Vasulka, cited prior, who introduced live-video processing practices to the gallery space. In this work, where video is an instrument, the gallery audience is invited to modulate sound and video oscillations and subsequently compose their own interactive (and performative) viewing experience.

In this sense, van Gelder has invented a video machine with sensory capacity in relation to the gallery environment, which defines the dispositif for this work. The artist says: 'This produces several layers of video which can be distinguished by their coloured channels, red, green and blue. The blue layer is the original source image from the video camera. This image produces shifts in the frequencies of the control-voltage which modulates every other oscillator' (P. van Gelder, private conversation 20 April 2018). In Eyes Without a Face, Van Gelder's deliberate misalignments determine the conditions for the audience to interact with the work and compose a moving image work via their own creative processes of experimentation delivered via hand gestures.

In another one of van Gelder's works, $A V$ Bells (van Gelder, 2011), the viewer again interacts with a series of signals, calibrated for the work, using glass 'bells' to change the audio-visual frequencies on the three monitors installed in the gallery. A crossing of signals creates various sounds and patterns on the monitors and this kind of cross-channelled, unexpected or 'misbehaving' feedback is what the audience is invited to explore. This represents another example where contingency, through error and chance, creates a critical distance from commodified and industrial modes of moving image production, for which stability is 
essential. It is the frictions, or accidents, which van Gelder exploits and places (literally) in the hands of the audience. She says:

I tend to connect things and play in the studio until I have something that seems to work ... I enjoy finding a patch that behaves in a way that is unexpected. Things get out of control and seem to start making themselves. If I can step back from the machine and look and listen and think 'How on earth is that happening?', then I'm happy. This takes a lot of fiddling and fine tuning, or knobbing." (P. van Gelder, private conversation 20 April 2018).

Knobbing in this context can be theorised as seeking nuanced and specific calibrations by tweaking multiple buttons and turning knobs on electronic devices such as bespoke synthesisers. The installation of both artworks discussed here, which are very much 'live' in the electrical sense, demand careful planning on behalf of the artist. The machines are designed to misbehave whilst remaining safe for public engagement. In the work of Pia van Gelder the moving image, via audiovisual apparatus, makes the work itself contingent upon an engagement of the user. This model of artist as 'facilitator' serves to critique conventional modes of authorship. Van Gelder's dispositifs are defined by a literal arrangement of parts in the form of an artists' machine - a digital continuation of analogue signal medium-specific video art of the 1960s-70s. 


\section{[3] Space}

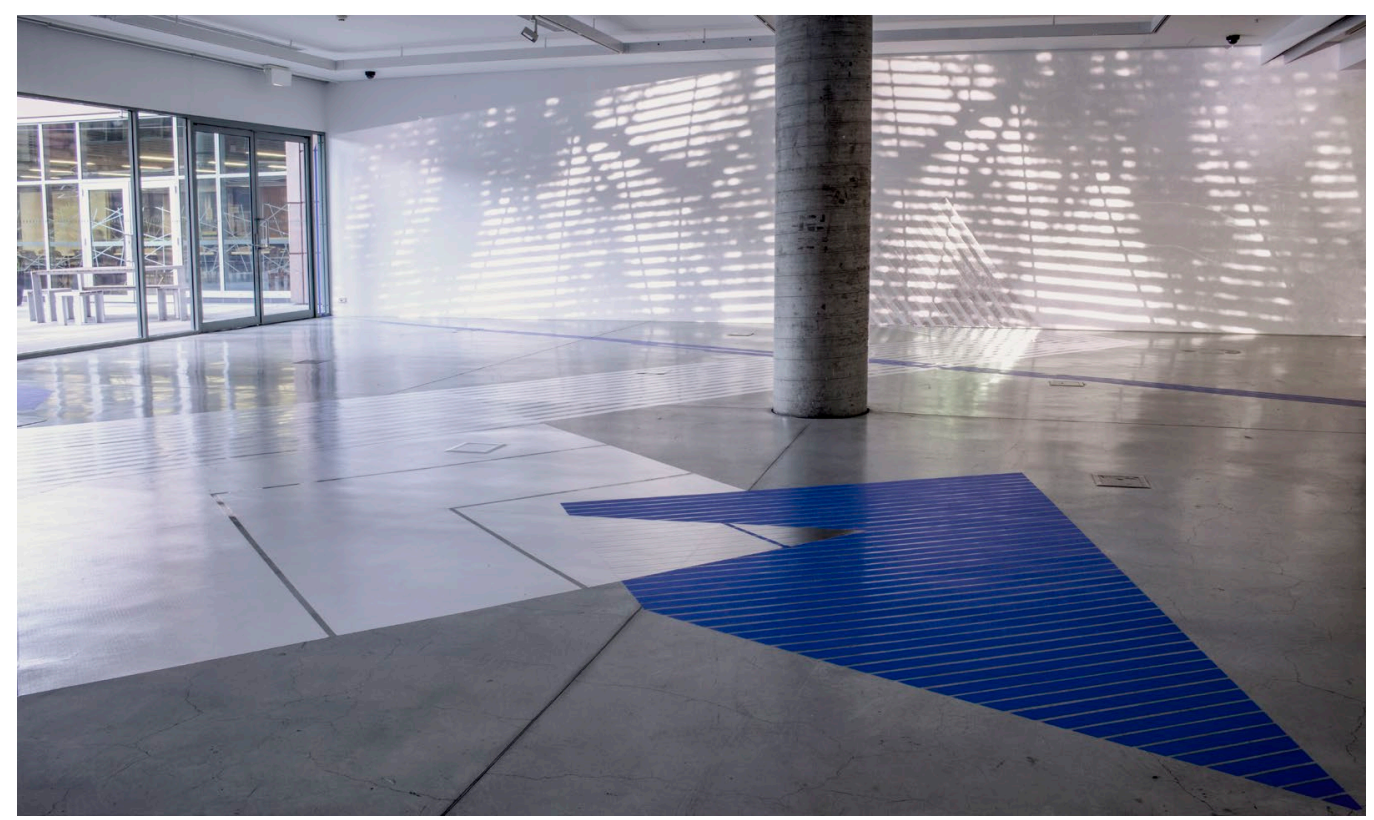

Figure 2: Biljana Jancic, Surface Tension (2017). Courtesy of the artists and UTS ART.

Photo: Biljana Jancic.

Biljana Jancic is a contemporary artist who works across media creating sculptural, surface articulated forms and moving image components, produced both with a camera lens and exploring default signals of audiovisual projection. She has a preference for industrial materials, and collides physical with virtual (moving image) forms in this context. For Jancic, a layering of forms 'complicate the relationship between the real and virtual dimensions of the image today' (B. Jancic private conversation 20 April 2018). She has developed a sitespecific practice to produce (often large scale) spatial interventions within the confines of the gallery. Her favoured materials include painted PVC pipe, reflective mirror tape, chromakey adhesives and the 'default' blue colour of digital projectors. Jancic juxtaposes moving image, alongside sculpture, painting and photography and her work can be situated, from an art history perspective, in relation to the suprematism of the early $20^{\text {th }}$ century and minimalism, since the 1960s, where artists have 'engaged the viewer in a phenomenological experience of objects in relation to the architectural dimensions of the gallery - not to pictorial space transforming actual space into a perceptual field' (Iles and Whitney Museum of American Art, 2001). In her practice, Jancic critiques the moving image as industrial projection, optical illusion and reflection, in order to transform the physical space of the gallery. 
The site-specificity of Jancic's dispositifs are of interest to this research into the ways artists approach installation of their work for the gallery. Surface Tension (Jancic, 2017), at UTS Art, consolidates the artist's work in A Beach (Beneath), for Primavera 2016 at the Museum of Contemporary Art (MCA), where she relied on the default, iridescent blue projections to critique the supposed neutrality of a prime metropolitan 'white box' art gallery space. This analysis of Surface Tension focuses on its conceptualisation and installation in relation to the history and architectonic qualities of the UTS Art gallery space, and explore the ways in which the artist responds to the gallery in an institutional context. UTS Art is only thematically a white cube space, in the sense that it is glazed, and susceptible to daylight, on its longitudinal axis. Rather than being a purpose-built art gallery, it was designed as a generic space for academic or commercial display prior to becoming home to the gallery. In an interview with UTS Art curator, Tania Creighton, the space was originally described as a generic 'mixed use' zone (T. Creighton private conversation, June 17 2018). The gallery operates as a kind of institutional 'fishbowl' defined by curtain-wall glazing, with views to an external courtyard to one side and a busy stairwell atrium on the other, congested with student traffic from the Faculty of Design, Architecture and Building at UTS. The gallery is naturally lit by vast amounts of daylight - a condition that has presented challenges for moving image artists, with the solution typically found in the installation of micro 'black boxes' for audio visual consistency. In contrast, for Jancic, daylight and the patterning of light and shadow across the gallery space formed a central part of her dispositif in this location.

In Surface Tension, Jancic develops site-specific 'moving images' for the gallery which take the form of: vectors of industrial aluminium 'mirror' tape (which reflect real-time movement in the gallery environment) and a two-channel projection of foliage and shadows, in response to the interplay of natural light seeping through the architectural brise soleil to the courtyard (Munt, 2017). For Claudia Arozqueta, this work, experienced as a 'compelling optical illusion leads to an ambiguous atmosphere: an intermediate space between indoors and outside' (Arozqueta, 2017). Consistent with our other case studies examined here, there is again contingency at play in relation to the reflectivity of the industrial materials combined with the reflections in the glazed surfaces of the gallery which produce an infinite variation of a subtle interplay of bodies, forms, light and space. Jancic draws our attention to the flicker of light and shadow play which dismantles the expectations of white cube style spaces. With respect to the large-scale projections, for Jancic, 'It wasn't so important to me that the images 
be well defined. I was much more interested in installing projections that looked like they were receding into the architecture and that felt like they were integrated into the space, rather than floating above it' (B. Jancic private conversation 2018). The 2-channel 'soft' blurred video images contrast with the late-modernist architectural language of the gallery to produce a dissolution, and merging, of interior and exterior space in the gallery.

\section{[4] Channels}

In the last decade, a clear trend in artists' moving image work has been towards a 'cinematic' aesthetic allied to the production values of industrial film production models. Here, the moving image artist takes the role of a film auteur - creatively directing the various 'departments' of production and post-production, from performance and choreography, to cinematography, production design (and costume) to post-production with respect to editing, colour grading, digital effects and nuanced sound design. In addition, 'talent' has been drawn from blockbuster cinema, including Cate Blanchett for Julien Rosefeldt's Manifesto (2014); Maggie Cheung and Zhao Tao for Isaac Julien's Ten Thousand Waves (2010); and James Franco for Julien's follow up work Playtime (2013). A rationale, for the convergence of Hollywood-style production aesthetics and artist moving image artworks is a case of both the high-profile exposure that a celebrity actor can bring to an (oversaturated) art market, and the recent shift to high-resolution digital moving image technologies that are affordable and accessible for artists today.

However, while moving image production for the black box and the white cube may increasingly share a cinematic aesthetic, there remains a clear differentiation when it comes to the dispositifs at play. For artists' moving image, 'the multiplication of screens may induce absorption into a panoramic spectacle' (Newman, 2009: 88). In Rosefeldt's Manifesto, 13 channels were utilised (each with a central performance by Blanchett), while Julien's immersive gallery 'films' rely on 9 channels for Ten Thousand Waves and 7 for Playtime. The dispositif shared by these artists dislocates the cinematic image from its fixed, singular screen position in a darkened theatre, to provide a much more fluid, and navigable, experience for a contemporary art audience. This conforms to the idea put forward by Chrissie Iles that, 'content becomes space and space content' as artists seek to engulf their audience 'with images and sound rather than physical walls' resulting in a dematerialisation of the fabric of the art gallery (Suderburg, 2000). 
The work of Australian moving image artist Angelica Mesiti is also consistent with industrial screen production models in her collaboration with film producers, cinematographers, sound designers and post-production creatives. Mesiti, whose work has been described in the popular media as 'cinematic and mesmerising' (Carey 2018), is Australia's representative for the $58^{\text {th }}$ Venice Biennale (2019). Her successful oeuvre is defined by explorations in the multimodality of language in human communication. The Colour of Saying (2015) is a 3channel moving image work in which a choir performs Serenade to Music (1938) in silence, using the hand gestures of sign language in lieu of vocal communication. The work is punctuated with moments of percussive clapping to mediate the 'silent' language, which extends to a rendition of Swan Lake, via hand gestures, to express the traditional steps in the choreography of the work (Mesiti website, Selected works). The Colour of Saying (2015) was installed in the above-mentioned Anna Schwartz gallery - the same year in which Brian Fuata recorded, then erased, his performance for Apparitional Charlatan in this very space.

For the installation of The Colour of Saying (2015), Mesiti carefully considered the placement of the three screens (channels), which were arranged obliquely in relation to the orthogonality of the white cube space. Most distinctive in Mesiti's dispositif for her large scale, multi-screen works (and in contrast to the international works discussed above) is her decision to ground the screens to the stratum of the floor. This is, in fact, the inverse of Julien's tendency to have screens that appear to 'float' in the installation of his works. For Mesiti's audience, this means the work is consumed at eye-level and that the images of the bodies that feature in the work reflect the human scale of being in the world.

To return to the views of Bree Pickering, where we started this chapter, Mesiti 'uses screen location to shift the viewer's relationship to the subject in the same way an installation artist or sculptor might - manipulating space to adjust the viewer's physical relationship to the work thereby generating a whole of body response' (B. Pickering, private conversation, June 2018). In relation to the anthropomorphic dimension of Mesiti's dispositif, she adds that although 'the multi-channel works seem monumental when first apprehended in an exhibition space, the experience of viewing each channel is intimate and quite personal, which is critical given the content' (B. Pickering private conversation, June 2018). Here, she identifies a correlation between Mesiti's preference for a specific horizontal dispositif and the social aspects of the work that deal with the physical performance, gesture and choreography of the body and its communicative potential. That is, 'for Mesiti, the body serves as both subject 
and object, a means with which to mark time and an instrument for creating rhythmic beats' (Richards, 2018).

\section{Conclusion}

For this chapter, devoted to new Australian artists' moving image in the gallery, our intuitions have been confirmed. That is, in our 'local' context there is evidence of a body of sophisticated, and nuanced, works which critically examine the ways in which moving image work is installed and received in contemporary gallery spaces. In this research we have employed the concept of the dispositif, frequently associated with film criticism, to further an understanding of artists' installation practices, and to offer a working term which can be utilised to speak to the diversity of arrangements in the apparatus and spatial display of the work, tightly integrated with its conceptual framework. The dispositifs at play in the diverse works represented here reflect both historical continuity with the history of the moving image in the gallery, and the ways in which these forms are remediated in the digital era. The impact of the democratisation of moving image production, its accessibility and affordability has been critical for production and post-production in this context.

The art gallery has historically presented moving image artists a problematic condition for the viewing and spectatorship of their work, due to levels of light and audio intrusion. However, in the work of the artists examined here, this very contingency of the gallery presents a renewed opportunity to engage with, critique, interact with or dematerialise the gallery. This new agenda finds form with regard to the specific dispositifs at play we have identified for each artwork and directly impact upon the audience experience. For Fuata, a performance work encased within an algorithmically generated OS screensaver; for van Gelder, the misbehaving oscillations of sound and video 'facilitated' by the artist; for Jancic, a sitespecific critique of the homogeneity of white cube gallery space; and for Mesiti, an embrace of the human scale in large-scale, immersive moving image works. The contemporary spaces here are all Sydney-based and our work suggests that this model of examining the conceptual foundations of Australian artist moving image work may be extended into other cities, territories, or indeed regional, and even remote, exemplars of artists' moving image work that seeks to engage diverse audiences with inventive and playful dispositifs in the gallery.

\section{References}

Arozqueta, C. (2017). Biljana Jancic at UTS Gallery. Retrieved from 
https://www.artforum.com/picks/biljana-jancic-67177

Balsom, E. (2013). Exhibiting cinema in contemporary art. Amsterdam: Amsterdam University Press.

Batty, C., \& Kerrigan, S. (2018). Screen Production Research: Creative Practice as a Mode of Enquiry. Cham, Switzerland: Palgrave Macmillan.

Bellour, R. (2012). La Querelle des dispositifs: Cinéma, installations, expositions. Paris: POL.

Bellour, R. (2018, The Quarrel of the Dispositifs: Reprise. Senses of Cinema, Retrieved from http://sensesofcinema.com/2018/cinema-and-the-museum/the-quarrel-of-the-dispositifs/

Burden, C. (1971). Shoot F Space, Los Angeles.

Comer, S. (2009). Film and video art. London: Tate.

Duguet, A. (1988). Dispositifs. Communications, 48(1), 221-242.

Fuata, B. (2015). Apparitional Charlatan - A Revisionist Account of an Arbitrary Historical Category of Dance Film is a Performance of our Time Together on Stage Before Class... Sydney: Carriageworks.

Giannachi, G., \& Westerman, J. (2017). Histories of Performance Documentation: Museum, Artistic, and Scholarly Practices. Milton: Routledge Ltd.

Goldsmith, K. (2011). Ubu Web. Retrieved from http://www.ubu.com/resources/

Iles, C. and Whitney Museum of American Art. (2001). Into the light: the projected image in American art, 1964-1977. New York: Whitney Museum of American Art.

Jancic, B. (2017). Surface Tension UTS Art. 
Manasseh, C. (2009). The problematic of video art in the museum, 1968-1990. Amherst, NY: Cambria Press.

Martin, A. (2014). Mise en Scène and Film Style: From Classical Hollywood to New Media Art. Houndmills, Basingstoke, Hampshire: Palgrave Macmillan.

Mesiti, A. (2015). The colour of saying. Sydney: Anna Schwartz Gallery.

Munt, A. (2017). Catalogue Essay: Surface Tension, UTS Art

Phelan, P. (1993). Unmarked: The Politics of Performance (1. publ. ed.). London u.a: Routledge.

Richards, B. (2018). Angelica Mesiti. Retrieved from https://nga.gov.au/installations/mesiti/default.cfm

Steyerl, H., \& Berardi, F. (2012). The wretched of the screen. Berlin; Cc2012: Sternberg Press.

Suderburg, E. (Ed.). (2000). Space, site, intervention. Minneapolis, Minn. ; Oxford: Univ. of Minnesota Press.

van Gelder, P. (2011). AV Bells . Melbourne: Westspace.

van Gelder, P. (2012). Eyes Without a Face. Sydney: Artspace. 